\title{
Mechanisms of prey size selection in a suspension-feeding copepod, Temora longicornis
}

\author{
Rodrigo J. Gonçalves ${ }^{1,2,3, *}$, Hans van Someren Gréve ${ }^{1}$, Damien Couespel $^{1}$, \\ Thomas Kiørboe ${ }^{1}$ \\ ${ }^{1}$ Centre for Ocean Life, DTU Aqua, Technical University of Denmark, Kavalergården 6, 2920 Charlottenlund, Denmark \\ ${ }^{2}$ Estación de Fotobiología Playa Unión, Casilla de Correos $N^{\circ} 15$ (9103) Rawson, Chubut, Argentina \\ ${ }^{3}$ Consejo Nacional de Investigaciones Científicas y Técnicas (CONICET), Av. Rivadavia 1917, Caba, Argentina
}

\begin{abstract}
We examined size-dependent prey detection and prey capture in free-swimming Temora longicornis using video observations, particle image velocimetry (PIV), and bottle incubations with phytoplankton prey sizes within the range 6-60 $\mu \mathrm{m}$ equivalent spherical diameter (ESD). T. longicornis generates feeding currents by oscillating its appendages at about $25 \mathrm{~Hz}$. Prey cells $>10 \mu \mathrm{m}$ ESD are perceived and captured individually. A capture response was elicited when prey was touched by (or within a few cell radii from) the setae on the feeding appendages. The extension of the setae defines the prey encounter cross section, which is therefore independent of prey size. The flux of water through the encounter area, estimated from PIV, was ca. $150 \mathrm{ml}$ ind..$^{-1}$ $\mathrm{d}^{-1}$, which represents the maximum possible clearance rates and was similar to that estimated in incubation experiments. However, while the detection probability was nearly $100 \%$ for cells $>10-15 \mu \mathrm{m}$, it declined rapidly for smaller cells. Conversely, the probability that a cell which elicited a capture response was actually ingested declined with increased cell size, from nearly $100 \%$ for small cells, to $\sim 0 \%$ for the largest cells examined. The resulting prey size spectrum, predicted as the product of the cell-size-specific encounter rates and capture probabilities, was domeshaped, with a maximum around 20-30 $\mu \mathrm{m}$ ESD. The prey size spectrum from incubation experiments had a similar shape and an optimum range of 30-50 $\mu \mathrm{m}$ ESD. The mechanistic underpinning of the prey size spectrum suggested here deviates from previous descriptions mainly in the mechanism and range of prey detection.
\end{abstract}

KEY WORDS: Temora longicornis · Calanoid copepods · Prey detection · Feeding currents · Prey capture $\cdot$ Zooplankton $\cdot$ Size spectrum $\cdot$ Prey size

\section{INTRODUCTION}

Zooplankton consume prey within a limited size range, which results in characteristic species-specific, dome-shaped prey size spectra. When considered over a broad range of zooplankton taxa and prey types, size transcends secondary prey characteristics, and the optimum prey:predator size (length) ratio averages near 1:10 (Kiørboe 2008). However, within this broad pattern, taxa-specific prey size optima, and variation around these optima, may vary by orders of magnitude (Hansen et al. 1994). Thus, filterfeeding pelagic tunicates typically feed on very small prey relative to their own size, less or much less than a prey:predator size ratio of 1:100 (Lombard et al. 2013), while ambush-feeding dinoflagellates feed on prey that approach or even exceed their own size (Hansen \& Calado 1999). These differences relate, at least in part, to differences in feeding mode. Thus, truly filter-feeding zooplankton can feed on prey that are just large enough to be retained on filters that are often fine-meshed (e.g. Sutherland et al. 2010), while 
grazers that perceive prey individually depend on prey that is large enough to produce a detectable signal, whether that signal is visual, chemical (olfaction or gustation), hydromechanical or tactile. Such considerations set the lower limits for prey size. Since larger prey will produce stronger signals, they are easier to detect or can be detected at a further distance, which determines the ascending part of the prey size spectrum. The descending part of the size spectrum and upper limit for prey size is ultimately set by the limited capacity to either capture or ingest large prey. The resulting prey size spectrum thus depends on the morphology of the grazer and on the mode of feeding and prey detection. Prey size spectra may have far-reaching implications for the composition and size-structure of pelagic ecosystems, and a mechanistic understanding of the underlying process may improve the validity of size-based models of pelagic food webs (Banas 2011, Wirtz 2012).

Pelagic copepods feed in 1 of 3 ways: (1) they cruise through the water and capture encountered prey, (2) they generate a feeding current from which they retrieve prey, or (3) they are ambush feeders that attack nearby-passing prey (Greene 1988, Tiselius \& Jonsson 1990, Kiørboe 2011). Regardless of their feeding mode, pelagic copepods mostly perceive and capture individual prey (Strickler \& Bal 1973, Koehl \& Strickler 1981, Paffenhöfer \& Lewis 1990), but they use different cues for prey perception. Ambush feeders use hydromechanical cues generated by their motile prey (Svensen \& Kiørboe 2000, Jiang \& Paffenhöfer 2004), cruising copepods use tactile cues and mechanoreception (Kjellerup \& Kiørboe 2012), while feeding-current feeding copepods use mechano- or chemoreceptors to perceive their prey. For feeding-current feeding copepods, Strickler (1982) reported that Eucalanus pileatus uses olfaction to remotely detect phytoplankton prey, while Tiselius et al. (2013) showed that Paracalanus parvus and Pseudocalanus sp. actually need to 'touch' the cell with the setae of the feeding appendages to detect their prey. The differences in detection modes may have implications for the lowest detection size and for the prey size spectra. Thus, ambush-feeding copepods appear to be preying on larger prey relative to their own size compared to cruise- and feeding-current feeding copepods (Wirtz 2012), probably because a larger prey is required to produce a detectable cue. In addition, prey reaction distances of the different prey detection mechanisms are expected to scale differently with prey size: for hydromechanical perception, the detection distance increases with prey radius multiplied by the square root of prey velocity (Kiørboe 2011); for remote detection using olfaction, the reaction distance increases with the prey odor leaking rate, which scales approximately with prey radius cubed (Tiselius et al. 2013); and for prey perceived by being touched, the prey detection distance is independent of prey size. Finally, the detection probability of a prey that comes within detection distance may depend on its size, and presumably typically would increase with prey size.

Here, we examine the mechanics of prey size selection in a feeding-current feeding copepod, Temora longicornis. We use direct high-speed video observations to describe prey detection and prey capture, flow visualization to estimate the feeding current velocity, and bottle incubations to estimate clearance rates. We show that prey size-dependent encounter rates and capture probabilities predict clearance magnitudes and a prey size spectrum that largely conform with those obtained in classical black-box incubation experiments, thus providing a mechanistic underpinning of observed prey size spectra.

\section{MATERIALS AND METHODS}

\section{Experimental organisms}

Copepods, Temora longicornis, originally collected in the Kosterfjorden and Øresund regions (Sweden-Denmark), were kept in a continuous culture at $14^{\circ} \mathrm{C}$, salinity 32 , and on a mixed phytoplankton diet consisting of Thalassiossira weisflogii, Heterocapsa triquetra and Rhodomonas salina at saturating concentrations. These algae, as well as other phytoplankton prey used in the experiments (see Table 1), were grown in repeated batch cultures. Only phytoplankton in exponential growth was used for experiments. We also used one ciliate as prey, the mixotrophic Mesodinium rubrum (grown in light and fed with the flagellate Teleaulax amphioxeia).

\section{Video observations of prey capture}

Between 10 and 20 adults and late copepodites $T$. longicornis (average $\pm \mathrm{SD}$ prosome length: $854 \pm$ $68 \mu \mathrm{m})$ were placed in small aquaria $(5-200 \mathrm{ml}$, mainly $67 \mathrm{ml}$ ) and acclimated without food for at least $1 \mathrm{~h}$ prior to filming to minimize effects of possible adaptation to previous prey types. Prey concentration was not quantified but was adjusted such that prey encounter rate was sufficiently high to allow observations of encounter events. Free-swimming individuals 
were filmed with a Phantom V210 high speed camera (resolution: $1280 \times 800$ pixels; frame rate: $2200 \mathrm{~Hz}$ ) in a dark, temperature-controlled $\left(16^{\circ} \mathrm{C}\right)$ room. Illumination was provided by an infrared lamp pointing through the aquarium towards the camera. The camera was equipped with lenses to yield a field of view of $3 \times 4.7 \mathrm{~mm}^{2}$ (ca. $3.7 \mu \mathrm{m}$ per pixel) and a depth of field of $290-430 \mu \mathrm{m}$. We also did previous trials with less magnification to observe behavior. Prey capture events that happened when the copepod was in focus were recorded. We used the following categorization of prey capture behavior (Fig. 1): When a prey was entrained in the feeding current and close enough to potentially trigger a capture reaction (based on previous observations), the event was recorded as a 'potential encounter'. This classification is somewhat subjective, since observations are made on 2-dimensional projections of events occurring in a 3-dimensional space, and some cells in the focal plane might still have been out of reach of the copepod. If a capture reaction was elicited by this cell, the event was further classified as an 'encounter', which in turn could end up as an 'ingestion', 'rejection' or 'miss'. The position of the prey cell relative to the copepod at the moment of a reaction was noted. For prey where no reactions were observed despite many potential encounters, only a few events were recorded to document the 'no reaction' case. In some cases, the copepod showed a capture response but the prey was not visible, or the animal exited the field of view while handling the prey. These cases were not taken into account.

Potential encounter (PE)

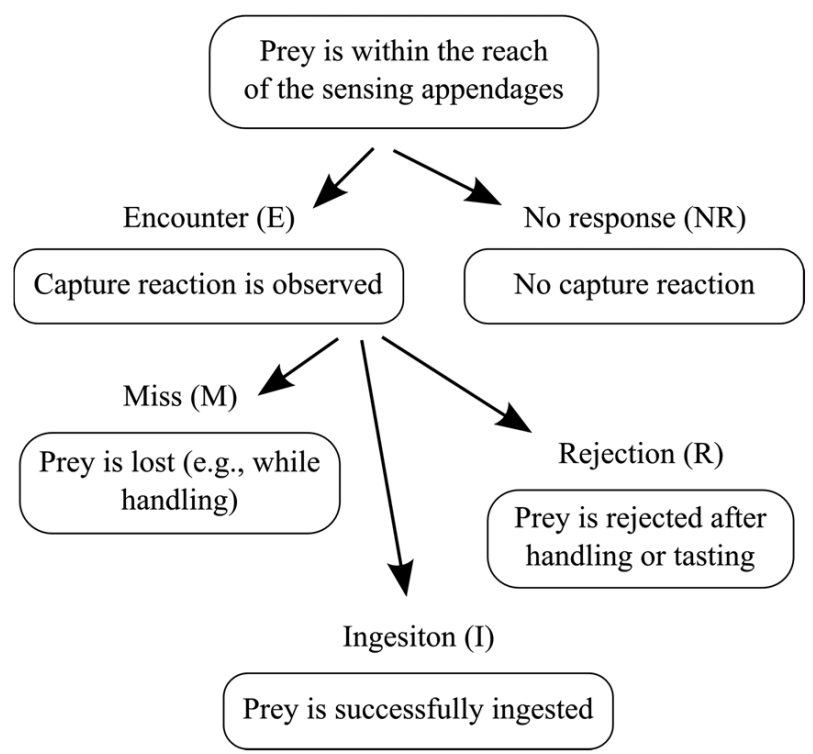

Fig. 1. Categories used for video observations of feeding behavior of Temora longicornis

\section{Flow visualization and estimation of maximum possible clearance rate}

When feeding, Temora longicornis is oriented with its long axis approximately vertical while creating a feeding current which flows downward (potentially carrying some entrained particles). As we shall describe in the 'Results', the video recordings demonstrate that only prey that are at most within a few cell radii from the setae of the feeding appendages elicit a capture response, and hence the area within reach of these setae defines the prey 'encounter area' in the video recording. We quantified the volume flux through this area by particle image velocimetry (PIV) to get an estimate of the volume of water scanned for food and hence of the maximum possible clearance rate.

For PIV, separate video recordings were obtained (as described in 'Video observations of prey capture'), except that (1) the source of illumination was an infrared (808 nm wavelength, $3 \mathrm{~W}$ power) pulsed laser sheet (ca. $0.3 \mathrm{~mm}$ width) directed in the camera's focal plane, and (2) tracer particles (Dantec Dynamics hollow glass spheres, median size $10 \mu \mathrm{m}$, density $1.1 \mathrm{~g} \mathrm{~cm}^{-3}$ ) were added to the water to trace fluid motion. The concentration of tracer particles was empirically adjusted to meet PIV needs (3-15 per interrogation area), but was otherwise not measured. These particles did not elicit capture reactions from the copepods. The recordings were made at the same magnification as described in 'Video observations of prey capture' and at $2000 \mathrm{~Hz}$. We recorded only frontal (i.e. ventral or dorsal) and lateral views of the copepods that were in the focal plane. The videos were analyzed with PIV software (DaVis 8.0, LaVision) to obtain velocity fields around the copepod. We analyzed 3 frontal and 3 lateral sequences (i.e. 6 individuals). Since 1 frontal and 1 lateral sequence are needed to calculate the flux, movies were paired based on matching prosome lengths of the recorded copepods. We masked out the copepod prior to analyzing the flow fields, which otherwise followed standard procedures. The feeding current is generated by the beating of the feeding appendages at about $25 \mathrm{~Hz}$ and the flow field varies somewhat during a beat cycle. We computed flow fields and streamlines averaged over 1 beat cycle, and analyzed 3 beat cycles for each individual. The average velocity of the copepod was subtracted to consider only the flow relative to the copepod.

To compute the flux through the encounter area, we first defined a line above the copepod that was perpendicular to the main body axis and 1 body 
A

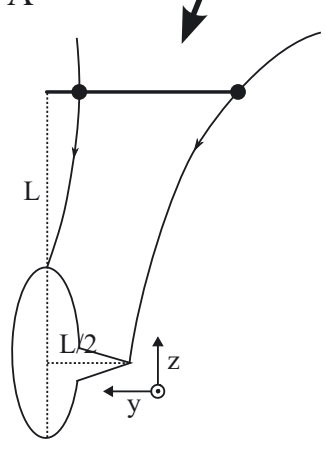

B

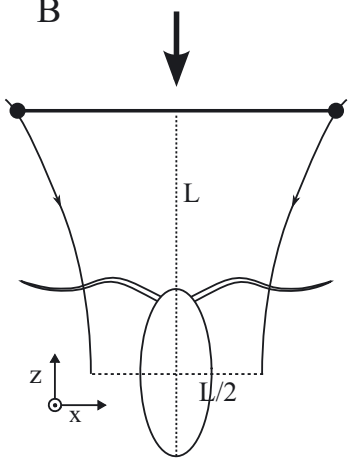

C

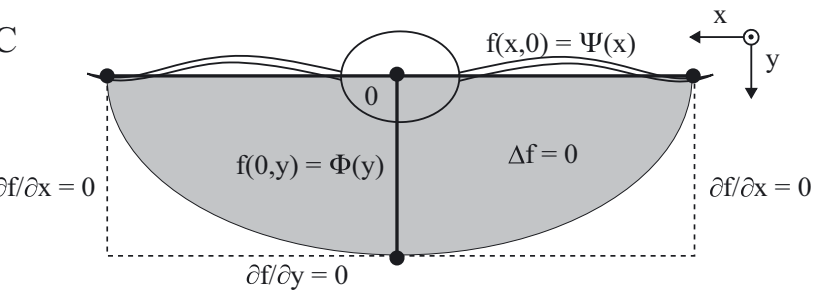

Fig. 2. Schematic of the criteria for the location of velocity profiles (lines with a black dot in both ends) in particle image velocimetry (PIV) analysis of Temora longicornis. L: body length (average of $854 \mu \mathrm{m}$; see 'Materials and methods'). Thick arrows on top: direction of the feeding current. Thin downward arrows: boundary streamline of the current used to calculate the flux. (A) Lateral and (B) frontal views of the copepod. (C) View from above and interpolation domain (rectangle), the boundaries and the area used to integrate the interpolated velocities and calculate the flux (grey area) (see Eqs. 1-4)

length away from the anterior tip of the copepod (Fig. 2A,B). The length of this profile line was defined by the 2 streamlines that passed the tips of the $2^{\text {nd }}$ antennae (dorsal/ventral view) and/or the body of the copepod (lateral view). The width of the capture area is approximately equal to half a prosome length from the main axis of the body (Fig. 2A,B). We then computed the orthogonal velocity profiles along these lines in lateral and dorsal/frontal views and subsequently combined these velocity profiles to obtain velocity profiles across the encounter area (Fig. 2C). We did this by interpolation as follows: If $x$ and $y$ are the axes for velocities over the frontal and lateral profiles, respectively, the function $f(x, y)$ was chosen such that (Fig. 2C):

$$
\begin{aligned}
& \Delta f=0 \quad \text { (inside the domain) } \\
& f(x, 0)=\psi(x) \\
& f(0, y)=\Phi(y) \\
& \partial f / \partial \mathrm{n}=0 \quad \text { (on the other boundaries) }
\end{aligned}
$$

where $f(x, y)$ is the orthogonal velocity across the area defined by both perpendicular profiles, and $\psi$ and $\Phi$ are the orthogonal velocities along the axis. For the other boundaries, we use a no-flux condition, $\partial f / \partial \mathrm{n}=0$, meaning the orthogonal velocity at the border of the domain is the same as its neighbor next to the border. The Laplace equation was used for the interpolation approach and was numerically solved using MATLAB (ver. 2013b, MathWorks). We used the central difference scheme to discretize $\Delta f$. Since the velocities at the intersection between the 2 profiles were not identical-which is required for interpolation since $\psi$ and $\Phi$ must have a common value in $(0,0)$ - we shifted the frontal velocities to match the lateral value or vice versa. For each interpolation, we therefore obtained 2 flux estimates. The flux was obtained by integrating the interpolated velocity over the area defined as a semi-ellipse within the interpolation domain (Fig. 2C). The calculated flux gives an estimate of the maximum possible clearance rate, assuming (1) $100 \%$ efficiency (i.e. every particle passing through the detection area is detected, captured and ingested), and (2) the feeding appendages are oscillating steadily.

\section{Clearance rates from bottle incubations}

Maximum prey-size-dependent realized clearance rates were estimated from functional response curves obtained by traditional bottle incubations (e.g. Frost 1972, Koski et al. 2005, Isari \& Saiz 2011). We used 11 different prey (diatoms and dinoflagellates) varying in size from 6.1 to $58.5 \mu \mathrm{m}$ equivalent spherical diameter (ESD; see Table 1). The dinoflagellate Akashiwo sanguinea was available in 2 different sizes (33.1 and $42.4 \mu \mathrm{m}$ ESD) and was therefore tested in 2 separate experiments.

Adult $T$. longicornis females were sorted using a large-mouth pipette under a dissection microscope and starved overnight before the experiment. Each prey species used as food was tested at 6 different concentrations that were matched between species based on prey carbon content. Cell carbon was estimated from cell volumes as measured by a Beckman Multisizer III Coulter Counter using the cell volume versus carbon relationship from Veloza et al. (2006) for R. salina, Putt \& Stoecker (1989) for M. rubrum and Menden-Deuer \& Lessard (2000) for all other species (according to whether they were diatoms or athecate or thecate dinoflagellates). Food suspensions were prepared in $0.2 \mu \mathrm{m}$ filtered seawater (salinity 32) with algal growth medium added. Six replicate bottles were prepared for each concentration: 3 bottles each with 5-12 copepods added, and 3 
bottles without copepods served as controls. The number of added copepods was varied to achieve $20-30 \%$ reduction in phytoplankton concentration during incubation at all prey concentrations (estimated from previous experience and trials). The bottles were mounted on a rotating plankton wheel ( $0.2 \mathrm{rpm})$ and incubated for $24 \mathrm{~h}$ at $14^{\circ} \mathrm{C}$ in the dark. At termination of the experiment, the copepods were checked for mortality, counted and measured ( $\mathrm{n}=$ 10), and prey concentrations were recorded on the particle counter. Ingestion and clearance rates and average prey concentrations during the experiment were calculated for each concentration (Kiørboe et al. 1982).

Holling Type II and Type III models were fitted to the measured ingestion rates (Kiørboe 2008, Schultz \& Kiørboe 2009):

$$
\begin{array}{ll}
\text { Holling II: } & I=\beta C(1+\tau \beta C)^{-1} \\
\text { Holling III: } & I=\alpha \beta \mathrm{e}^{1-\alpha / C}
\end{array}
$$

where $\beta$ is the maximum clearance rate $\left(\mathrm{ml} \mathrm{d}^{-1}\right), \tau$ is the prey handling time (d) (Eq. 5) and $\alpha$ is the prey concentration $(\mu \mathrm{gC})$ where the clearance rate is highest (Eq. 6). $C$ is the prey concentration $(\mu \mathrm{gC})$. The Holling III approach is probably better than a lower feeding threshold because $T$. longicornis generates a (reduced?) feeding current even in the absence of food (Yule \& Crisp 1983).

\section{RESULTS}

\section{Feeding current, prey perception and prey capture}

Feeding current generation in Temora longicornis is described in van Duren et al. (2003) and is similar to that described for most other calanoids (Koehl \& Strickler 1981, Gill \& Poulet 1988, Tiselius et al. 2013). Briefly, all feeding appendages oscillate in a regular, synchronous but out of phase pattern at about $25 \mathrm{~Hz}$, and the current is driven mainly by the second antenna (A2) and the maxillipeds (Mxp). The A2 and Mxp beat in almost opposite phases, making the average feeding current steady between beat cycles. The flow is mainly anterior-posterior, but also has a ventral-dorsal component (Fig. 2A).

Prey entrained in the feeding current may be captured if perceived. Prey perception, as evidenced by a capture response, always happens when a prey cell is within a few cell radii of the setae of one of the feeding appendages (which presumably means the cell is 'touched'), most often A2. A capture response is typically initiated by one or more of the feeding appendages becoming desynchronized from the normal non-capture beating pattern. The particle thereby deviates from its initial trajectory and it is redirected, either by being pushed by an appendage, or the copepod flings the maxillae (Mx) and/or Mxp open to suck in a parcel of water that contains the particle. Both cases result in the particle being moved towards the mouth region. Prey capture often includes stretching one of the feeding appendages (typically Mxp, which has greater angular freedom of movement and far-ranging capture distance) to redirect the cell towards the mouth. In some cases, a capture response involves reorientation of the body to capture a cell which was initially out of reach of the Mxp. If, for example, A2 perceives a cell, the copepod may quickly turn its orientation (mostly using the antennules, and to a lesser extent with the urosome) to re-position its body in such a way that the feeding appendages have higher chances of catching the cell. This whole event lasts less than a beat cycle. Videos showing examples of prey captures (Video_01a-c, Video_02, Video_03) are available in the Supplement at www.int-res.com/articles/suppl/ m517p061_supp/.

When the cell is close to the mouth, the maxilla and mandible start the ingestion by pushing the cell into the mouth. The swimming legs can help with subtle repositioning during the whole process, which may be concluded by the cell being swallowed. The handling time, i.e. the time from first reaction till the cell has been ingested, ranges between 140 and $514 \mathrm{~ms}$ and increases with the size of the cell being handled (Fig. 3). While the copepod attempts to ingest the cell (mostly with $\mathrm{Mx}$ and mandible), A2 and Mxp do not interrupt the beating and therefore keep producing the feeding current.

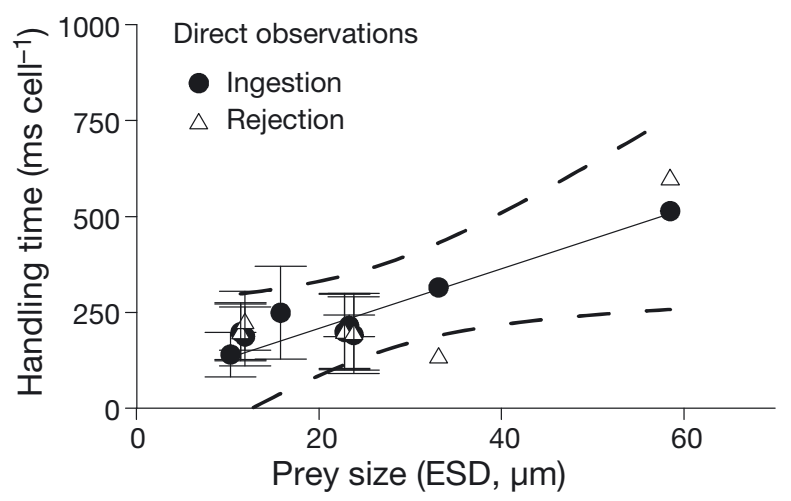

Fig. 3. Temora longicornis. Handling time as a function of prey size. Data from video observations. Handling time is defined as the duration of the period between the capture reaction and ingestion or rejection. ESD = equivalent spherical diameter. Dashed lines: $95 \%$ confidence intervals 


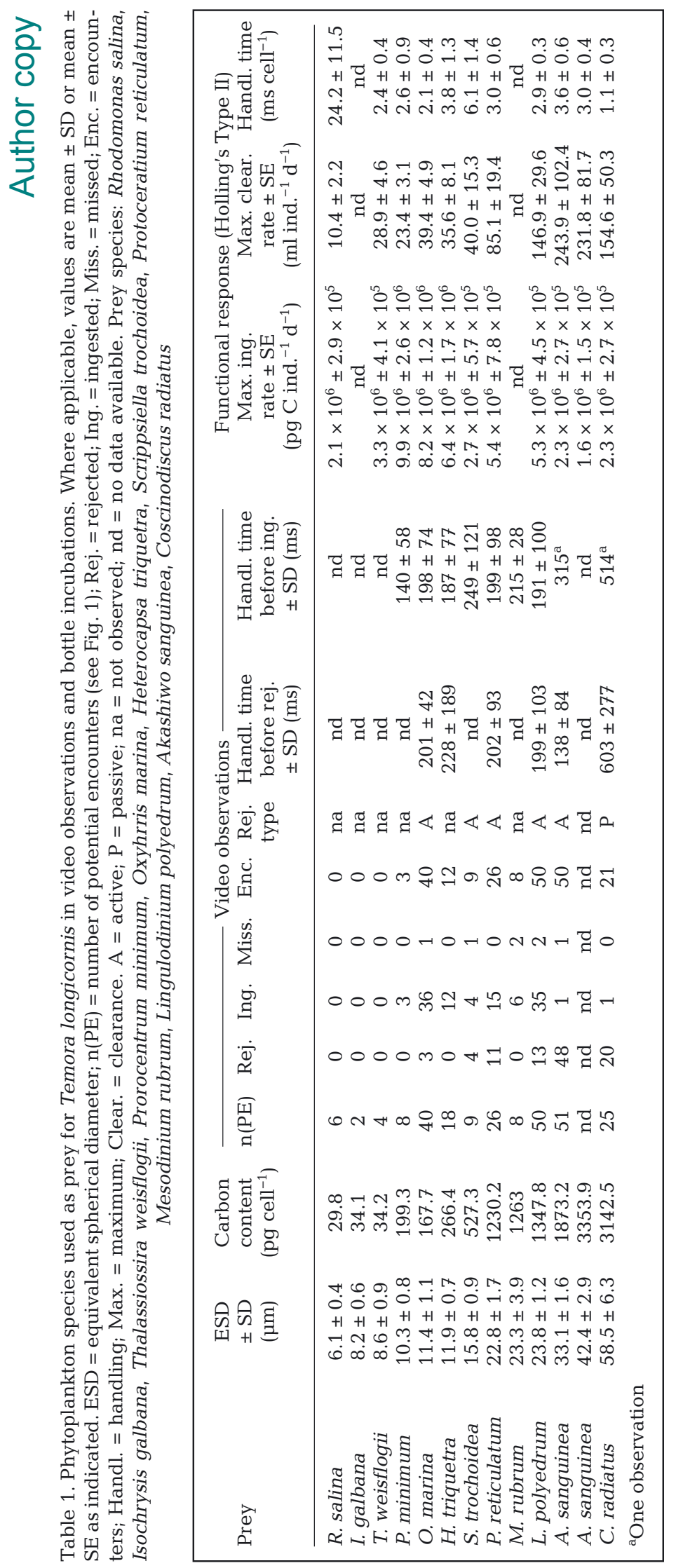

Very few cells were missed in the capture process, but some were captured and then rejected (Table 1). Of the prey examined here, only the ciliate Mesodinium rubrum has evasive behavior and a significant swimming speed, i.e. comparable to that of the feeding current. This prey often escaped the feeding current even before the copepod showed a capture response (Video_04 in the Supplement), but in a few cases, $M$. rubrum managed to escape even after being detected. Cells of the other species were missed in only a few cases. We observed 2 different types of rejection. Both occurred after capture reaction and handling. One occurred when the copepod started to flap the Mx and Mxp, until the particle was pushed away; we label this 'active rejection' (see Video_05 in the Supplement). The duration of active rejection varied between 140 and $230 \mathrm{~ms}$ and was independent of prey cell size. Other cells were rejected because they were apparently too big to swallow; we label this 'passive rejection'. The copepod handled the cell for about $0.5 \mathrm{~s}$, trying to fit the cell into its mouth, and then rejected it (see Video_06 in the Supplement).

\section{Prey-size and prey-type dependent responses}

We did not observe capture reactions to (or ingestion of) the smallest cells examined in the video recordings, while about $50 \%$ of the cells of $\sim 10 \mu \mathrm{m}$ ESD and nearly $100 \%$ of the cells $>10 \mu \mathrm{m}$ ESD that were within reach of the feeding appendages elicited a capture response (Fig. 4A). The probability of detection thus increases steeply around $10 \mu \mathrm{m}$ ESD.

Capture success, on the other hand, decreased with cell size (Fig. 4B). The smallest cells were captured with nearly $100 \%$ success, while the largest cells examined were almost all rejected. Except for the largest cell examined, the $60 \mu \mathrm{m}$ diatom Coscinodiscus radiatus, all unsuccessful cell captures (dinoflagellates and the ciliate) were rejected by the active method, while the large diatom was rejected by the passive method after attempts to ingest it. The prey size spectrum predicted from the product of detection probability and capture success peaks in the region of 10 to ca. $33 \mu \mathrm{m}$ and declines for smaller and larger prey sizes (Fig. 4C).

\section{Feeding current}

PIV accurately describes the feeding current that accelerates towards the copepod feeding appendages (Fig. 5A,B). Maximum velocities were ob- 

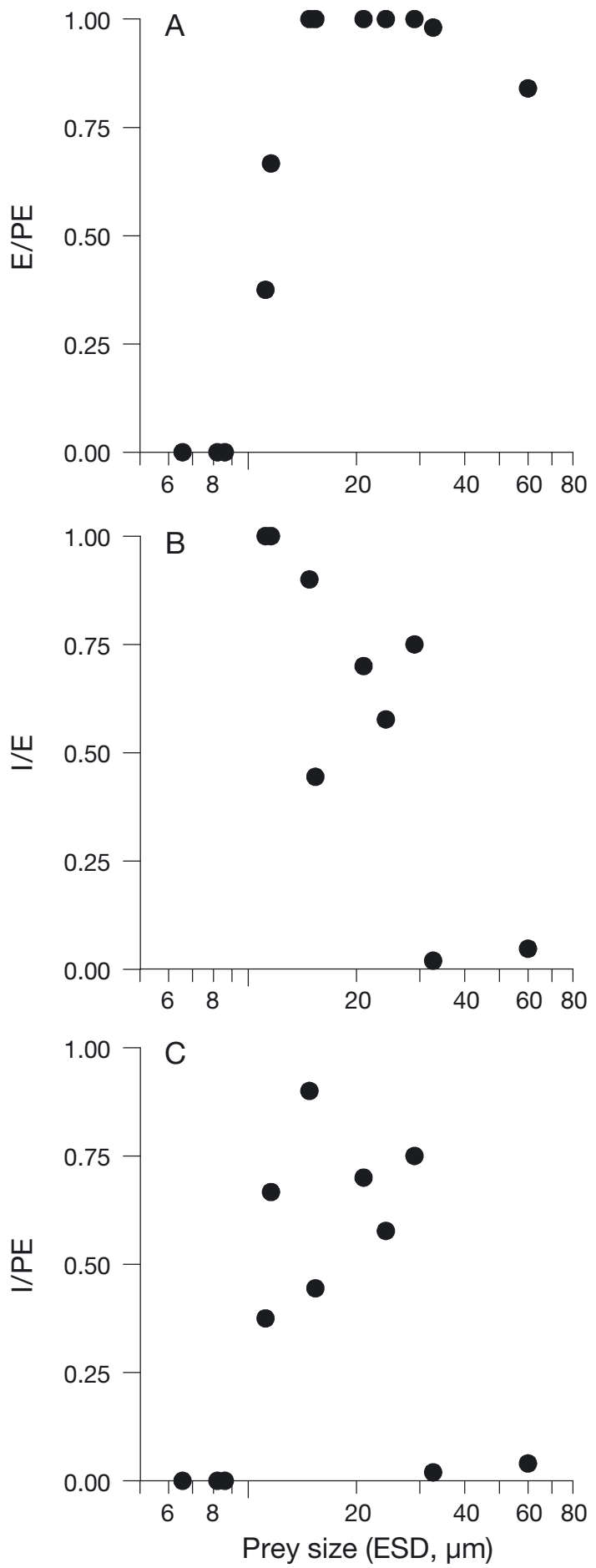

Fig. 4. Temora longicornis. Capture data from video observations, according to prey size. (A) E/PE denotes the fraction of potential encounters (PE) which elicited a capture response (i.e. 'encounter', E). (B) I/E denotes the fraction of encounters (E) in which the prey was effectively ingested (I). Since some values of E are zero, some data points would include division by zero and therefore were removed. (C) I/PE denotes the fraction of potential encounters (PE) which ended in ingestion (I). Note the logarithmic scale of the $x$-axis. ESD = equivalent spherical diameter served near the tip of the setae and in the core of the current (Fig. 5). The streamlines are well defined when averaged over a beat cycle. The estimated flux through the encounter region varied between 112 and $193 \mathrm{ml}$ ind. ${ }^{-1} \mathrm{~d}^{-1}$, and averaged $147 \pm 24 \mathrm{ml}_{\text {ind. }}{ }^{-1}$ $\mathrm{d}^{-1}$ (mean $\left.\pm \mathrm{SD}\right)$ (Table 2$)$.

\section{Functional responses, maximum clearance rates, and prey size spectrum}

T. longicornis ingested all prey species at concentration-dependent rates (Fig. 6). The ingestion rate increased with prey concentration towards an asymptotic maximum and the clearance rate declined at high prey concentrations in all experiments. In some cases, clearance rates also declined at the lowest concentration. We therefore fitted both Holling Type II and Type III responses to the functional response data, which yielded similar estimates of maximum clearance and ingestion rates (Fig. 7A). There was no clear relationship between maximum ingestion rates in terms of carbon and prey size (Fig. 7A), but the estimated time spent with each ingested prey (handling time per cell) increased with increasing cell size (Fig. 7B). The handling time estimated this way was ca. 3-4 orders of magnitude longer than the handling time measured by direct observations (Fig. 3).

The prey size spectrum derived from maximum clearance rates estimated in bottle incubations ( $\beta$ in Eqs. 5 \& 6) were dome-shaped and peaked for cell sizes $30-50 \mu \mathrm{m}$ and declined for smaller and larger cell sizes (Fig. 8A). The pattern was independent of whether a Holling Type II or Type III was assumed. The clearance rate magnitude estimated from video observations (Fig. 8B) and flux estimates (Table 2) were similar to those derived from bottle incubations, but prey size spectra derived from direct observations were biased toward smaller cells compared to those derived from bottle incubations.

\section{DISCUSSION}

\section{Prey size}

Body size is often considered a master trait in traitbased description of ecological communities (Litchman \& Klausmeier 2008) because most vital rates (e.g. growth, metabolism, feeding) and other important features of an organism (e.g. prey size selection) correlate to its size. This is one reason that size-based models of marine ecosystems, for example, are pres- 

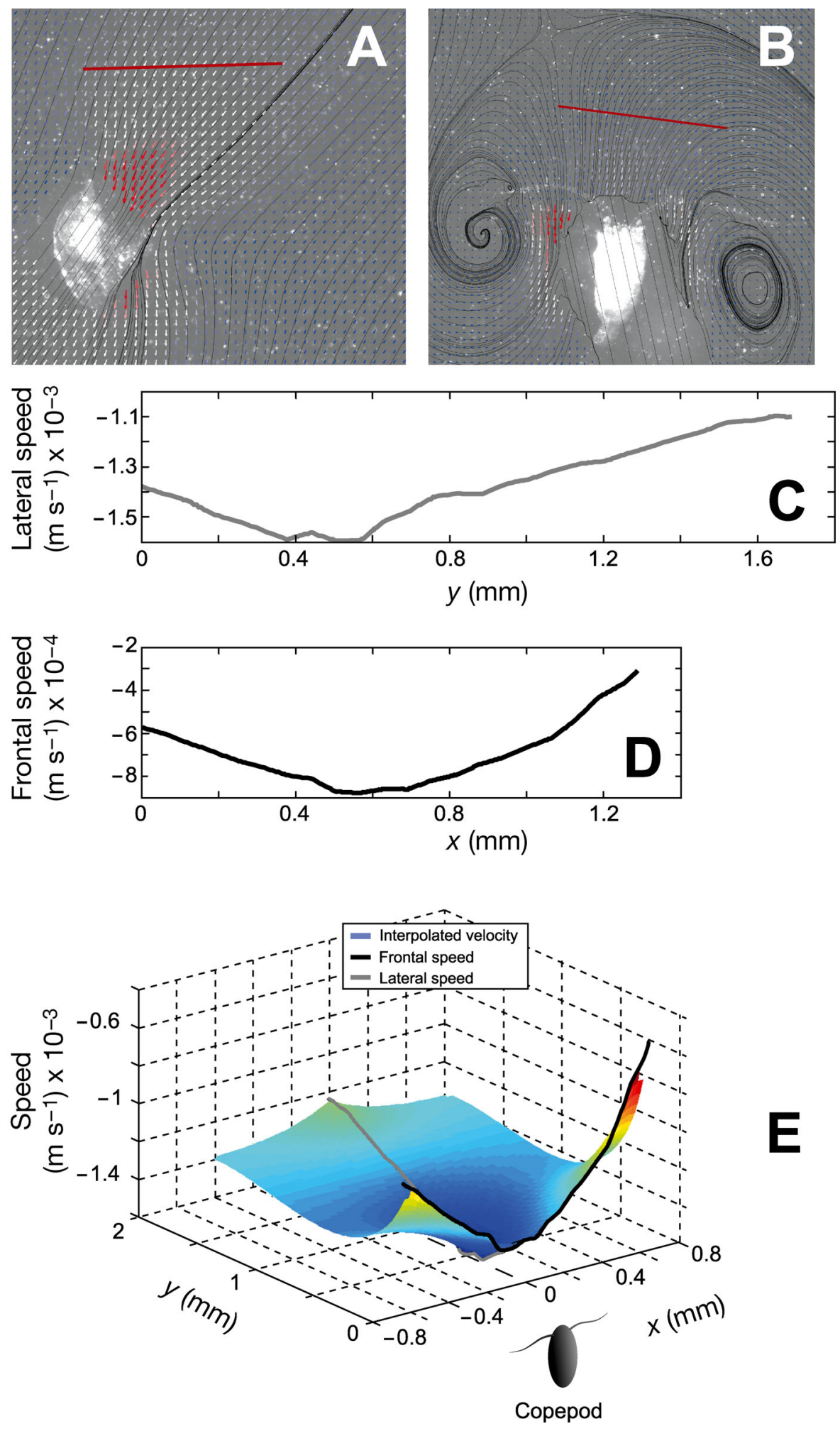

Fig. 5. Particle image velocimetry (PIV) analysis of Temora longicornis. Velocity fields from videos of (A) lateral and (B) frontal views. Arrows indicate vector velocity for each cell; blue, white, red for low, medium, high speeds, respectively. Black thin isolines represent streamlines. Red thick line indicates the location of the speed profiles in (C,D). The copepod is shown for illustrative purposes. Distribution of speed along the profile line in the (C) lateral and (D) frontal view (values are negative because it is a downward direction). (E) Interpolated velocity: high (dark blue) to low (dark red) speeds, over the area defined by the 2 profiles above the copepod for a selected PIV sequence. The integration domain is a semi-ellipse within this interpolated velocity area (see Fig. 2C) 
Table 2. Result of particle image velocimetry (PIV) analysis of Temora longicornis from video recordings. For each copepod (numbered 1-6), 3 beat cycles were analyzed. Each copepod was filmed either from the side (lateral view) or from the front/back (frontal view), from which values were combined in pairs. For each combination of 2 views of similarly sized copepods, 2 values of flux are obtained, according to which one is used as the upper limit. Flux is shown as average \pm SD

\begin{tabular}{|lccc|}
\hline Pair & Copepod & Size $(\mu \mathrm{m})$ & Flux $\left(\mathrm{ml} \mathrm{ind.} .^{-1} \mathrm{~d}^{-1}\right)$ \\
\hline 1 & 1 & 815 & $133.21 \pm 3.80$ \\
& 2 & 807 & $122.42 \pm 8.61$ \\
2 & 3 & 754 & $139.03 \pm 7.45$ \\
& 4 & 716 & $132.46 \pm 14.33$ \\
3 & 5 & 700 & $185.08 \pm 11.72$ \\
& 6 & 720 & $169.85 \pm 2.24$ \\
\hline
\end{tabular}

ently being developed with some success (Andersen \& Beyer 2006, Fuchs \& Franks 2010, Zhou et al. 2010, Banas 2011). However, as noted by Wirtz (2012), there are secondary traits, such as feeding mode, that may have important implications for size-dependent trophic interactions and the structure of pelagic communities and, hence, for the development of traitbased models. Prey size spectra have been recorded for a number of copepod species by classical grazing experiments (e.g. Fernández 1979, Berggreen et al. 1988), and optimal prey size appears to depend strongly on feeding mode, even within this one taxonomic entity (Wirtz 2012). The present study is the first attempt to directly relate a prey size spectrum derived from a black-box bottle experiment to direct observation and quantification of the underlying encounter and prey capture mechanisms in a copepod. Such mechanistic underpinning of observed prey size spectra may help in understanding other species with similar feeding modes.

Clearance rate of Temora longicornis is a function of prey size (O'Connors et al. 1980) and concentration. Dam \& Lopes (2003) noted that studies of the functional response of $T$. longicornis are few and are restricted to diatoms or natural plankton assemblages as food sources. Previous studies showed higher clearance rates on 'medium-size' cells (25$100 \mu \mathrm{m})$ (Daro 1985) and for lower concentrations (Dam 1986, Dam \& Peterson 1991). However, the food size spectrum was not fully characterized, and sometimes the observed relationship of ingestion versus prey concentration is linear $\left(\mathrm{O}^{\prime}\right.$ Connors et al. 1980, Dam \& Peterson 1991). Food size and type are known to affect grazing rates of this copepod, but the optimum size and mechanisms are not well understood (Dam \& Lopes 2003, Gentsch et al. 2009).
Grazing is the result of a suit of sequential events: encounter, detection, capture, and ingestion (Holling 1959). The size-dependencies of the rates and probabilities of each component determine the resulting prey size spectrum. Feeding rates are strongly dependent on prey concentration, as evidenced by functional response curves (Fig. 6), but 2 parameters of the functional response are constants, viz., the maximum clearance rate $\beta$, and the maximum ingestion rate $I_{\max }=\tau^{-1}$. The difference between the cell handling time estimated from direct video observations and the handling time parameter $\left(\tau^{-1}\right)$ estimated from the functional response suggests that the maximum ingestion rate is limited by post-capture processes (mainly digestion; see 'Handling' below), rather than by the time it takes to handle individual prey cells (Figs. 3 \& 7B). Therefore, $I_{\max }$ varies independent of prey size (Fig. 7A) and is an inadequate measure of prey preference. The maximum clearance rate, however, is exactly the product of the components of predation. These components correspond to what we have quantified by direct observations and flow visualization, and hence the maximum clearance rate is the property of choice to characterize prey size spectra.

The prey size spectrum derived from bottle incubations for T. longicornis resembles the dome-shaped spectra reported for other pelagic copepods, and the range of optimum prey:predator size ratios $(0.04-$ 0.012 for max. clearance rate, data not shown) is within the range reported for feeding-current feeding copepods (Hansen et al. 1994). The prey size spectrum derived from direct observations and flow visualization is similar in shape and clearance magnitude as that derived from bottle incubations (Fig. 8), although it is more variable and apparently slightly narrower. In the following section we discuss the mechanisms of the components of predation for this feeding-current feeding copepod and the deviations between the size spectra obtained by the 2 methods, and we compare our measurements to reports in the literature.

\section{Prey encounter rate}

The feeding current brings the prey within reach of the copepod, while the feeding current flux through the sensory area determines the volume of water that the copepod scans for prey per unit time and, hence, the maximum possible clearance rate. How are cells perceived? Our observations confirm most other reports for a variety of feeding-current feeding copepods, in that prey cells are perceived when they are 'touched' by (or within a few cell radii from) the setae 

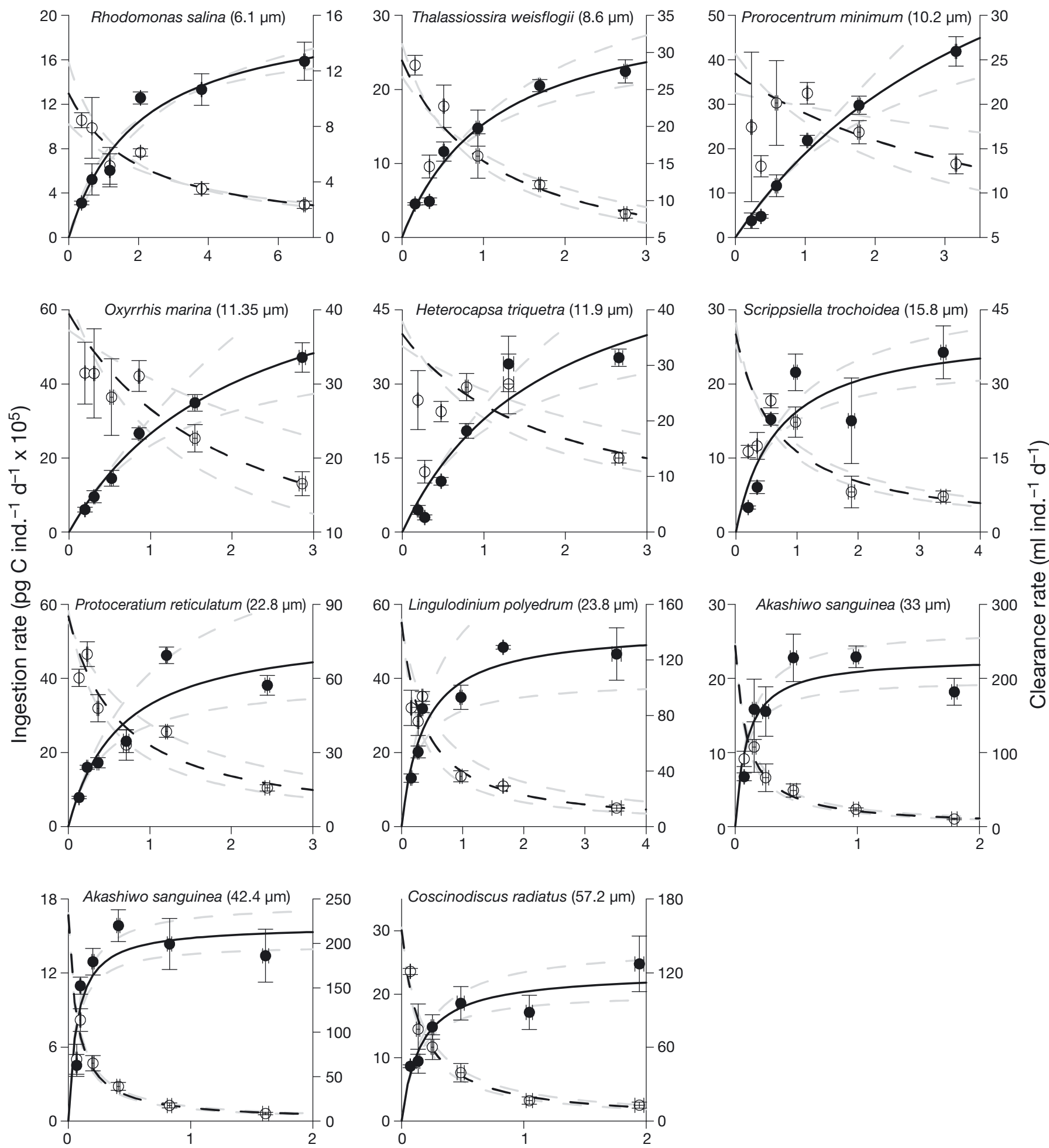

Average prey concentration $\left(\mathrm{pg} \mathrm{C} \mathrm{ml} \mathrm{m}^{-1} \times 10^{5}\right)$

Fig. 6. Functional response of Temora longicornis to different prey sizes. Ingestion (black symbols, in pg carbon ind. ${ }^{-1} \mathrm{~d}^{-1}$ ) and clearance rates (white symbols in $\mathrm{ml}$ ind.$^{-1} \mathrm{~d}^{-1}$ ) as functions of average prey concentration (pg $\mathrm{C} \mathrm{ml}{ }^{-1}$ ) during the experiment. Vertical and horizontal error bars indicate \pm 1 SE of the mean value of 3 replicates. Black solid lines are fits of Holling Type II functional responses (Eq. 5) to ingestion rates and black dashed lines are fits to clearance rates. Grey dashed lines are $95 \%$ confidence intervals. Estimates of parameters of the fitted model are given in Table 1 . Note the different scales of the $x$ - and 

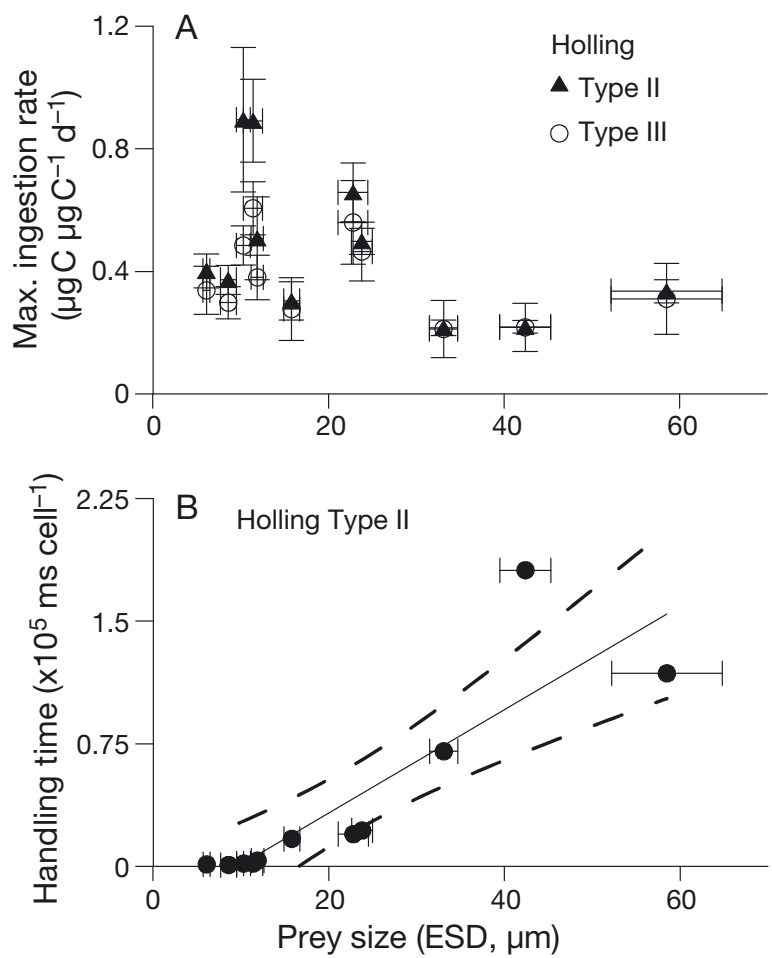

Fig. 7. Temora longicornis. (A) Carbon-specific maximum ingestion rates as estimated by Holling Type II and Type III. Maximum ingestion rates ( $\mu \mathrm{g} \mathrm{C}$ ingested per $\mu \mathrm{g} \mathrm{C}$ copepod per day) are estimated from the functional response. (B) Handling time estimated from the Holling Type II model. Error bars indicate $\pm 1 \mathrm{SE}$. $\mathrm{ESD}=$ equivalent spherical diameter

on the feeding appendages (Price et al. 1983, Koehl 1984, Paffenhöfer \& Lewis 1990, Bruno et al. 2012, Tiselius et al. 2013). This is different from an earlier report that the copepod Eucalanus pileatus can perceive cells remotely at a distance of 1 body length (Strickler 1982) using olfaction and chemical cues that arrive in the sheared feeding current at the copepod's sensors prior to the prey cell itself (Andrews 1983, Jiang et al. 2002). From the observational evidence, it is impossible to decide whether the cue used by T. longicornis is mechanical/tactile, mediated through the viscous boundary layer, or chemical (gustatory). However, the implication of the observation is that prey detection distance is largely independent of cell size since it is mainly determined by the length of the setae on the feeding appendages, and the encounter cross section is therefore defined by the region reached by the setae of the feeding appendages. This would allow the estimation of the encounter cross section in T. longicornis from morphological measurements. Based on the various reports cited (Price et al. 1983, Koehl 1984, Paffenhöfer \& Lewis 1990, Bruno et a. 2012, Tiselius et al. 2013), we suggest that this could be a general
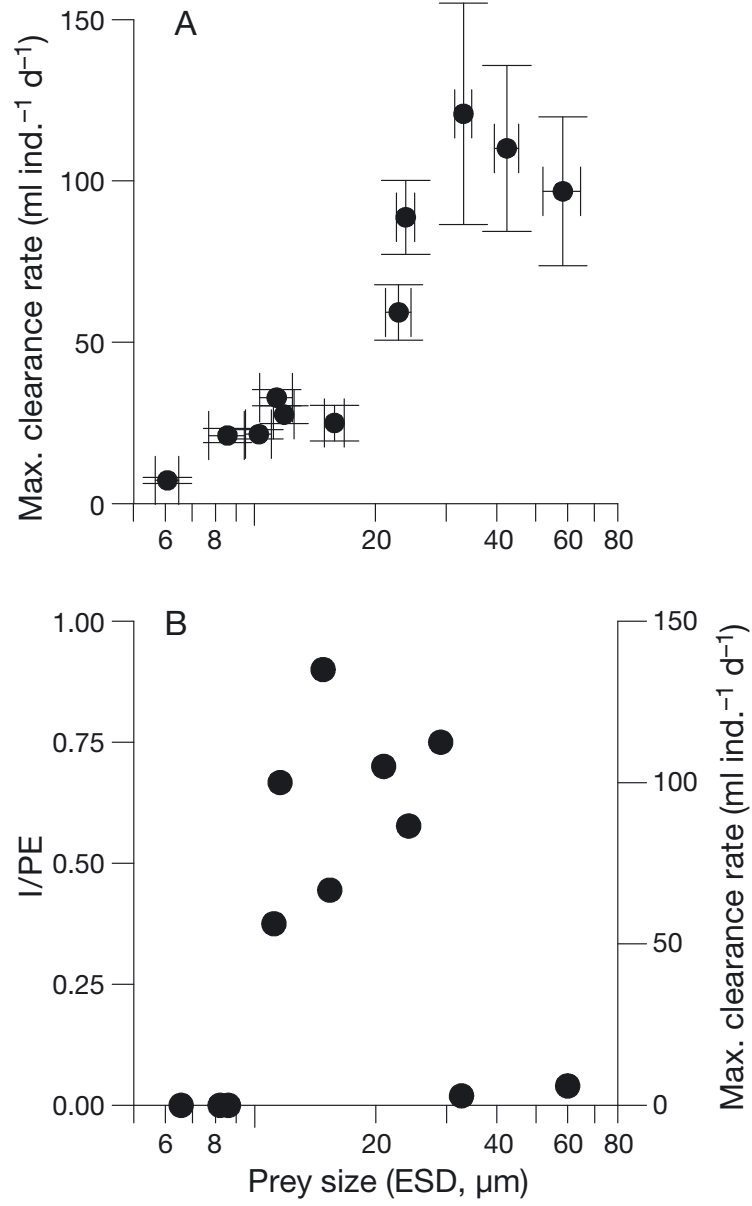

Fig. 8. Temora longicornis. Maximum clearance rates as a function of prey size. (A) Predicted maximum clearance rates by Holling Type III model from bottle incubation data. (B) Capture success (I/PE: the fraction of potential encounters which ended in ingestion) probability obtained from video observations as compared to maximum clearance rates estimated from particle image velocimetry (PIV). Note the logarithmic scale of the $x$-axis. ESD = equivalent spherical diameter

pattern of non-motile prey detection in other feeding-current feeding copepods. Ambush feeders and others that depend on motile prey generating a fluid signal are different (e.g. Jiang \& Paffenhöfer 2004). The perception distance and, hence, encounter region, depend on the intensity of the signal generated by the swimming prey, and the flux of prey through the encounter region of a stationary ambush feeder thus depends mainly on the swimming speed and size of the prey (Svensen \& Kiørboe 2000).

Our PIV-based estimate of the flux through the encounter area, about $150 \mathrm{ml} \mathrm{d}^{-1}$, is similar to that reported by Tiselius \& Jonsson (1990), $133 \mathrm{ml} \mathrm{d}^{-1}$. The more sophisticated approach used here shares a fundamental problem with the simpler particletracking method used by Tiselius \& Jonsson (1990), 
namely that we observe 2-dimensional sections of a 3-dimensional flow. We have tried to circumvent this problem by combining flow observations from 2 different directions, but our estimate is still an approximation. However, it is of the same magnitude as the clearance rate actually measured on cells of optimal cell size, which in turn is consistent with the observation that these cells are perceived with nearly $100 \%$ efficiency (Fig. 4A).

Detection probability is strongly dependent on prey cell size, and the very abrupt increase in detection probability from 0 to nearly $100 \%$ at a cell size around $10 \mu \mathrm{m}$ ESD is striking. Eucalanus pileatus similarly responds to $12 \mu \mathrm{m}$ cells but not to $6 \mu \mathrm{m}$ cells (Price et al. 1983), while Paracalanus parvus responds to cells as small as $6 \mu \mathrm{m}$ (Tiselius et al. 2013) as do nauplii of T. longicornis (Bruno et al. 2012). Thus, the detection threshold may vary somewhat between species, but there obviously is a lower size limit for detection of individual prey. According to bottle incubation experiments, however, $T$. longicornis still feeds on cells as small as $6 \mu \mathrm{m}$, albeit at a low rate. E. pileatus and E. elongatus similarly feed on cells smaller than the detection limit (Price et al. 1983, Price \& Paffenhöfer 1986), and we have observed the same apparent discrepancy between direct observations and bottle incubations in other copepods (Acatia tonsa, Calanus finmarchicus; T. Kiørboe unpubl.). These small cells are not perceived and captured individually, and how they are cleared from suspension is unknown. Price et al. (1983) and Price \& Paffenhöfer (1986) suggested that small cells were collected on the setae of the $2^{\text {nd }}$ maxillae by low-amplitude oscillations of the feeding appendages, but the exact mechanism was not revealed. In any case, due to the capture of (but lack of a visible response to) small cells, the prey size spectrum predicted from direct observations is truncated at small sizes as compared to the spectrum derived from bottle incubations.

\section{Capture}

Most capture responses resulted in prey capture. Mesodinium rubrum is the only one of the prey species that is known to be evasive and, in fact, these cells can perform very fast escape jumps, corresponding to about 500 cell lengths $\mathrm{s}^{-1}$ (Fenchel \& Hansen 2006, and the present study). M. rubrum may perceive and escape the feeding current before it is perceived by the copepod (Video_04 in the Supplement), and therefore such cells were never encountered. Without an escape jump, they might have passed through the encounter area. Therefore, the behavior of the prey may lead to deviations from the simple sized-based encounter model used here and to lower clearance rates than suggested by the smooth, domeshaped prey size spectrum recorded for non-evasive prey species in this study ( $M$. rubrum was not tested in bottle incubations). We argue that, unlike clearance rates, the mechanics of food capture is largely independent of food concentration and consistent throughout our observations.

\section{Handling}

Handling times estimated from video observations and from Holling model fits differed by orders of magnitude. This is because the 2 methods estimate different properties: observed handling time is the time required to handle each captured cell (preingestion handling), while the handling time parameter estimated from bottle incubations is the time constant of the rate-limiting process, which is the processing capacity of the gut, not the time to handle individual cells (e.g. Wirtz 2013).

\section{Ingestion}

Many cells were rejected upon capture, and hence not ingested. The biggest cells tested here were apparently too big for routine ingestion and they were rejected after the copepod had tried to eat the cell. In all other cases with smaller cells, the rejection was 'active': the copepod 'tasted' the cell, and then rejected it. We refrain from a more detailed interpretation of the difference between these rejection behaviors.

The high rejection frequency for the largest cells leads to the predicted prey size spectrum being truncated in the large size end relative to that recorded in bottle incubations. For the very largest cells (Coscinodiscus radiatus), however, sample size (i.e. number of events recorded in video observations) is insufficient. Even at maximum feeding rate, T. longicornis only ingested 1 of these large cells per 2 minutes. Even after several hours of video observations, we could only record feeding events which occurred entirely within the field of view (and in focus), and it therefore would take days of video observations and more patience than we had to get sufficient statistics for such 'rare' events. A similar argument only partly applies to the high rejection rate recorded for Akashiwo sanguinea ( 0.8 cells ingested $\mathrm{min}^{-1}$; Table 1$)$, and the difference between predicted and observed clearance rate on 
these cells appear to be real, although unexplained. Whether that is because the nutritional value of the cells differed between the 2 types of experiments (performed 6 mo apart), we do not know. In a previous video experiment with the copepod Paracalanus parvus (Tiselius et al. 2013), we observed that the rejection rate of captured dinoflagellates (Heterocapsa triquetra) differed significantly between the 2 experimental sessions 6 mo apart. Others have similarly reported that cells of a suitable size are not ingested, either because they are toxic (Demott 1989, Teegarden 1999) or have low nutritional value (Cowles et al. 1988). Thus, nutritional value or other characteristics of some taxonomic groups of prey may cause deviations from a simple prey-size-based description of prey preference. Further, such characteristics may vary within a species depending on growth conditions (Cowles et al. 1988).

Yet another possible reason for the discrepancy between bottle incubations and video observations is effects of acclimation to prey types. Small effects of prior acclimation on feeding rates have previously been reported for other copepods (Price \& Paffenhöfer 1984), and we cannot entirely rule out such effects, because the duration of the 2 types of experiments ( $24 \mathrm{~h}$ bottle incubations; $\sim 2 \mathrm{~h}$ video observations) yield different acclimation periods.

While the largest cells examined here are ingested only at a low rate, $T$. longicornis may at times eat much larger particles. In wild-caught copepods, Jansen (2008) reported that $T$. longicornis can capture and take 'bites' of the $380 \mu \mathrm{m}$ Coscinodiscus wailesii to ingest some of the cell content, and Lombard et al. (2013) reported that also acclimated, wild-caught $T$. longicornis can colonize and feed on mm-sized marine snow aggregates, again by taking bites of the aggregate.

\section{CONCLUSIONS}

Despite the deviations between observed and predicted prey size spectra discussed above, our observations provide a reasonable basis for a mechanistic underpinning of prey size selection in Temora longicornis, which could also apply to other feedingcurrent feeding as well as to cruise-feeding copepods. The prey detection mechanisms appear to be the same for several (most?) species of copepods and depend on very close contact with prey cells. The lower prey size for perception appears to vary rather little between a $200 \mu \mathrm{m}$ T. longicornis nauplius and $2 \mathrm{~mm}$ Eucalanus pileatus copepodite (Price et al. 1983, Bruno et al. 2012), while larger species of copepods may be able to handle larger cells, and relative prey size spectra may therefore be rather similar between differently sized copepods, consistent with observations (Hansen et al. 1994). We also argue that ambush-feeding copepods may have a rather different lower size limit for prey detection than the more active feeding modes, because the detection mechanism is different and depend on fluid mechanical cues generated by the swimming prey. Thus it is not only differences in morphology but also differences in feeding mode, even within 1 taxonomic unit, that determines the food size spectra of zooplankton.

Acknowledgements. The Centre for Ocean Life is funded by the VKR Foundation. R.J.G. was supported by CONICET and FONCYT (PICT 2438), and additional support was received from The Danish Research Council for Independent Research. Phytoplankton cultures were obtained from Dr. Gert Hansen at the Scandinavian Culture Collection of Algae \& Protozoa (SCCAP), University of Copenhagen, and cultures of Mesodinium rubrum from Dr. Per Juel Hansen, University of Copenhagen. Jack Melbye maintained cultures of copepods and phytoplankton, and Dr. Uffe H. Thygesen supervised the estimation of flux from PIV measurements.

\section{LITERATURE CITED}

Andersen KH, Beyer JE (2006) Asymptotic size determines species abundance in the marine size spectrum. Am Nat 168:54-61

Andrews JC (1983) Deformation of the active space in the low Reynolds number feeding current of calanoid copepods. Can J Fish Aquat Sci 40:1293-1302

Banas NS (2011) Adding complex trophic interactions to a size-spectral plankton model: emergent diversity patterns and limits on predictability. Ecol Model 222: 2663-2675

> Berggreen U, Hansen B, Kiørboe T (1988) Food size spectra, ingestion and growth of the copepod Acartia tonsa during development: implications for determination of copepod production. Mar Biol 99:341-352

Bruno E, Borg CMA, Kiørboe T (2012) Prey detection and prey capture in copepod nauplii. PLoS ONE 7:e47906

> Cowles TJ, Olson RJ, Chisholm SW (1988) Food selection by copepods: discrimination on the basis of food quality. Mar Biol 100:41-49

> Dam HG (1986) Short-term feeding of Temora longicornis Müller in the laboratory and the field. J Exp Mar Biol Ecol 99:149-161

Dam HG, Lopes RM (2003) Omnivory in the calanoid copepod Temora longicornis: feeding, egg production and egg hatching rates. J Exp Mar Biol Ecol 292:119-137

$>$ Dam HG, Peterson WT (1991) In situ feeding behavior of the copepod Temora longicornis: effects of seasonal changes in chlorophyll size fractions and female size. Mar Ecol Prog Ser 71:113-123

Daro MH (1985) Field study of the diel, selective and efficiency feeding of the marine copepod Temora longicornis in the Southern Bight of the North Sea. In: Van Grieken R, Wollast R (eds) Progress in Belgian oceanographic research. Proceedings of a Symposium held at the Palace of Academies, Brussels, 3-5 March 1985. University of Antwerp, Antwerp, p 250-263 
Demott WR (1989) Optimal foraging theory as a predictor of chemically mediated food selection by suspensionfeeding copepods. Limnol Oceanogr 34:140-154

Fenchel T, Hansen PJ (2006) Motile behaviour of the bloomforming ciliate Mesodinium rubrum. Mar Biol Res 2:33-40

Fernández F (1979) Particle selection in the nauplius of Calanus pacificus. J Plankton Res 1:313-328

Frost BW (1972) Effects of size and concentration of food particles on the feeding behavior of the marine planktonic copepod Calanus pacificus. Limnol Oceanogr 17:805-815

Fuchs HL, Franks PJS (2010) Plankton community properties determined by nutrients and size-selective feeding. Mar Ecol Prog Ser 413:1-15

> Gentsch E, Kreibich T, Hagen W, Niehoff B (2009) Dietary shifts in the copepod Temora longicornis during spring: evidence from stable isotope signatures, fatty acid biomarkers and feeding experiments. J Plankton Res 31: 45-60

Gill CW, Poulet SA (1988) Impedance traces of copepod appendage movements illustrating sensory feeding behaviour. Hydrobiologia 167-168:303-310

> Greene CH (1988) Foraging tactics and prey-selection patterns of omnivorous and carnivorous calanoid copepods. Hydrobiologia 167-168:295-302

> Hansen PJ, Calado AJ (1999) Phagotrophic mechanisms and prey selection in free-living dinoflagellates. J Eukaryot Microbiol 46:382-389

Hansen B, Bjørnsen PK, Hansen PJ (1994) The size ratio between planktonic predators and their prey. Limnol Oceanogr 39:395-403

Holling CS (1959) The components of predation as revealed by a study of small-mammal predation of the European pine sawfly. Can Entomol 91:293-320

Isari S, Saiz E (2011) Feeding performance of the copepod Clausocalanus lividus (Frost and Fleminger, 1968). J Plankton Res 33:715-728

Jansen S (2008) Copepods grazing on Coscinodiscus wailesii: a question of size? Helgol Mar Res 62:251-255

> Jiang H, Paffenhöfer GA (2004) Relation of behavior of copepod juveniles to potential predation by omnivorous copepods: an empirical-modeling study. Mar Ecol Prog Ser 278:225-239

> Jiang H, Osborn TR, Meneveau C (2002) Chemoreception and the deformation of the active space in freely swimming copepods: a numerical study. J Plankton Res 24:495-510

Kiørboe T (2008) A mechanistic approach to plankton ecology. Princeton University Press, Princeton, NJ

- Kiørboe T (2011) How zooplankton feed: mechanisms, traits and trade-offs. Biol Rev Camb Philos Soc 86:311-339

> Kiørboe T, Møhlenberg F, Nicolajsen H (1982) Ingestion rate and gut clearance in the planktonic copepod Centropages hamatus (Lilljeborg) in relation to food concentration and temperature. Ophelia 21:181-194

> Kjellerup S, Kiørboe T (2012) Prey detection in a cruising copepod. Biol Lett 8:438-441

Koehl MAR (1984) Mechanisms of particle capture by copepods at low Reynolds numbers: possible modes of selective feeding. In: Meyers DG, Strickler JR (eds) Trophic dynamics within aquatic ecosystems. Westview Press, Boulder, CO, p 135-166

Koehl MAR, Strickler JR (1981) Copepod feeding currents: food capture at low Reynolds number. Limnol Oceanogr 26:1062-1073

Koski M, Dutz J, Klein Breteler WCM (2005) Selective grazing of Temora longicornis in different stages of a Phaeocystis globosa bloom-a mesocosm study. Harmful Algae 4:915-927

> Litchman E, Klausmeier CA (2008) Trait-based community ecology of phytoplankton. Annu Rev Ecol Evol Syst 39: 615-639

Lombard F, Koski M, Kiørboe T (2013) Copepods use chemical trails to find sinking marine snow aggregates. Limnol Oceanogr 58:185-192

Menden-Deuer S, Lessard EJ (2000) Carbon to volume relationships for dinoflagellates, diatoms, and other protist plankton. Limnol Oceanogr 45:569-579

O'Connors HB Jr, Biggs DC, Ninivaggi DV (1980) Particlesize-dependent maximum grazing rates for Temora longicornis fed natural particle assemblages. Mar Biol 56:65-70

Paffenhöfer GA, Lewis KD (1990) Perceptive performance and feeding behavior of calanoid copepods. J Plankton Res 12:933-946

Price HJ, Paffenhöfer GA (1984) Effects of feeding experience in the copepod Eucalanus pileatus: a cinematographic study. Mar Biol 84:35-40

> Price HJ, Paffenhöfer GA (1986) Capture of small cells by the copepod Eucalanus elongatus. Limnol Oceanogr 31: 189-194

Price HJ, Paffenhöfer GA, Strickler JR (1983) Modes of cell capture in calanoid copepods. Limnol Oceanogr 28:116-123

Putt M, Stoecker DK (1989) An experimentally determined carbon: volume ratio for marine 'oligotrichous' ciliates from estuarine and coastal waters. Limnol Oceanogr 34: 1097-1103

> Schultz M, Kiørboe T (2009) Active prey selection in two pelagic copepods feeding on potentially toxic and nontoxic dinoflagellates. J Plankton Res 31:553-561

Strickler JR (1982) Calanoid copepods, feeding currents, and the role of gravity. Science 218:158-160

Strickler JR, Bal AK (1973) Setae of the first antennae of the copepod Cyclops scutifer (Sars): their structure and importance. Proc Natl Acad Sci USA 70:2656-2659

Sutherland KR, Madin LP, Stocker R (2010) Filtration of submicrometer particles by pelagic tunicates. Proc Natl Acad Sci USA 107:15129-15134

> Svensen C, Kiørboe T (2000) Remote prey detection in Oithona similis: hydromechanical versus chemical cues. J Plankton Res 22:1155-1166

> Teegarden GJ (1999) Copepod grazing selection and particle discrimination on the basis of PSP toxin content. Mar Ecol Prog Ser 181:163-176

Tiselius P, Jonsson PR (1990) Foraging behaviour of six calanoid copepods: observations and hydrodynamic analysis. Mar Ecol Prog Ser 66:23-34

> Tiselius P, Saiz E, Kiorboe T (2013) Sensory capabilities and food capture of two small copepods, Paracalanus parvus and Pseudocalanus sp. Limnol Oceanogr 58:1657-1666

van Duren LA, Stamhuis EJ, Videler JJ (2003) Copepod feeding currents: flow patterns, filtration rates and energetics. J Exp Biol 206:255-267

Veloza AJ, Chu FLE, Tang KW (2006) Trophic modification of essential fatty acids by heterotrophic protists and its effects on the fatty acid composition of the copepod Acartia tonsa. Mar Biol 148:779-788

Wirtz KW (2012) Who is eating whom? Morphology and feeding type determine the size relation between planktonic predators and their ideal prey. Mar Ecol Prog Ser 445:1-12

Wirtz KW (2013) How fast can plankton feed? Maximum ingestion rate scales with digestive surface area. J Plankton Res 35:33-48

> Yule AB, Crisp DJ (1983) A study of feeding behaviour in Temora longicornis (Müller) (Crustacea:Copepoda). J Exp Mar Biol Ecol 71:271-282

Zhou M, Carlotti F, Zhu Y (2010) A size-spectrum zooplankton closure model for ecosystem modelling. J Plankton Res 32:1147-1165

Submitted: March 5, 2014; Accepted: September 10, 2014

Proofs received from author(s): November 15, 2014 